\section{Incidência cumulativa anual de doenças musculoesqueléticas incapacitantes relacionadas ao trabalho em uma área urbana do Brasil}

\author{
Cumulative annual incidence of disabling work- \\ related musculoskeletal disorders in an \\ urban area of Brazil
}

Norma Suely Souto Souza 1

Vilma Sousa Santana 2

\title{
Introdução
}

1 Auditoria Regional em Salvador, Instituto Nacional do Seguro Social, Salvador, Brasil.

2 Instituto de Saúde Coletiva, Universidade Federal da Bahia, Salvador, Brasil

Correspondência N.S. S. Souza Auditoria Regional em Salvador, Instituto Nacional do Seguro Social.

Rua Augusto Lopes Pontes 1211, apto. 1803, Salvador, BA 41760-035, Brasil. nsouto@uol.com.br

\begin{abstract}
This study focused on the annual cumulative incidence (ACI) of disabling work-related musculoskeletal disorders affecting the neck and/or upper limbs (ULMSD) among workers covered by the National Social Insurance System in the city of Salvador, Bahia State, Brazil. Cases were workers who received disability compensation benefits when unable to work due to ULMSD, during the year 2008. The data were obtained from the administrative systems of the National Social Insurance Institute and Ministry of Labor and Employment. ACI was 15 per 10,000 workers. Increased ACI of ULMSD was associated with female gender, lower income, and work in financial activities or manufacturing. Women earning the minimum wage (US\$64.00 per month) or less had the highest ACI of ULMSD (123 per 10,000), suggesting inequalities in the occurrence of these disorders. The study indicates the need to prioritize preventive actions focusing on ergonomics and work organization, early diagnosis, treatment, and rehabilitation.
\end{abstract}

Cumulative Trauma Disorders; Insurance Benefits; Occupational Health; Incidence
Doenças musculoesqueléticas compreendem as enfermidades inflamatórias e degenerativas dos músculos, nervos, tendões, juntas, cartilagens e discos intervertebrais, as quais podem resultar em dor e limitação funcional. Em diversos países, representam a maior causa de recebimento de compensações por dias perdidos no trabalho, notadamente quando relacionadas a este. Nos Estados Unidos, por exemplo, as doenças musculoesqueléticas compõem $52,2 \%$ das que geraram benefícios do Seguro de Compensação dos Trabalhadores 1 . No Canadá, essas enfermidades corresponderam a $54,4 \%$ dos casos de doenças ocupacionais com afastamento do trabalho 2 . Na França, constituíram-se em 63\% das enfermidades relacionadas ao trabalho que receberam compensação previdenciária ${ }^{3}$. No Brasil, em 2006, 48,2\% dos benefícios previdenciários por doença do trabalho foram concedidos por causa das doenças musculoesqueléticas (Ministério da Previdência Social. Informações estatísticas gerais da previdência social. http://creme.dataprev. gov.br/infologo/GCON/Ver07.php, acessado em 31/Mar/2008), enquanto, na Bahia, em 2000, essas doenças predominaram $(84,5 \%)$ entre aquelas ocupacionais com afastamento do trabalho por mais de 15 dias, com base nos benefícios do sistema de previdência social 4 .

Em decorrência da importante carga de incapacidade gerada, esses agravos causam expressi- 
vo impacto social e econômico, representado por baixa qualidade de vida dos trabalhadores incapacitados, perda de produtividade, dias de trabalho perdidos, custos com assistência médica e pagamentos de compensação previdenciária. Nos Estados Unidos, custos com pagamentos de compensação por dias de trabalho perdidos por doenças musculoesqueléticas relacionadas ao trabalho variaram de 13 a 20 bilhões de dólares anualmente. Somados com os custos indiretos, representados por perda de renda, perda de produtividade, esses valores podem atingir 45 a 54 bilhões de dólares 5 .

Dentre as doenças musculoesqueléticas relacionadas ao trabalho, aquelas que acometem a região cervical e/ou os membros superiores, também conhecidas como LER/DORT (lesões por esforços repetitivos/distúrbios osteomusculares relacionados ao trabalho), têm se destacado não só pela frequência com que têm sido diagnosticadas, mas também por atingir indiscriminadamente trabalhadores de diversos ramos de atividade 6,7. Além disso, a duração da incapacidade entre trabalhadores com doenças musculoesqueléticas na região cervical e/ou membros superiores é maior quando comparada à de outros agravos. Estudo sobre benefícios ocupacionais no Estado de Washington, Estados Unidos, mostrou que a duração média, de 159 dias, dos benefícios concedidos por síndrome do túnel do carpo, um dos tipos mais frequentes de doenças musculoesqueléticas na região cervical e/ou membros superiores, foi a maior entre todos os outros benefícios 8 .

Apesar da importância desses agravos na morbidade da população trabalhadora, não foram encontrados estudos nacionais sobre a sua incidência, em especial a dos casos que cursaram com incapacidade. No país, investigações comumente estimam a prevalência de sintomatologia relativa às doenças musculoesqueléticas, entre algumas categorias ocupacionais. Dessa forma, pesquisas que estimem a incidência das doenças musculoesqueléticas incapacitantes na região cervical e/ou membros superiores poderão descrever seu impacto na população trabalhadora, caracterizando os indivíduos afetados. Em adição, será possível identificar subgrupos em maior risco para a ocorrência e gravidade do evento, a fim de direcionar ações relativas à prevenção e à reabilitação profissional.

O presente estudo estima não só a incidência cumulativa anual das doenças musculoesqueléticas na região cervical e/ou membros superiores relacionadas ao trabalho que geraram benefícios por incapacidade, como também seus padrões de distribuição sociodemográfico e ocupacional, no Município de Salvador, Bahia, em 2008.

\section{Métodos}

Este estudo descritivo foi conduzido com todos os trabalhadores que integram o Regime Geral da Previdência Social (RGPS) no Município de Salvador, Bahia, em 2008, com exceção dos empregados domésticos e contribuintes individuais. Estes, por não serem cobertos pelo Seguro Acidente do Trabalho, não fazem jus a benefícios acidentários, que são os benefícios previdenciários relacionados a agravos - acidente ou doença - decorrentes do trabalho. Como os funcionários públicos estatutários não estão incluídos no RGPS, eles também não integraram a população estudada.

Os casos foram compostos por trabalhadores que receberam benefício da espécie 91 - assim denominado o benefício acidentário por incapacidade temporária - decorrente de doenças musculoesqueléticas na região cervical e/ou membros superiores, em sua primeira entrada no sistema em 2008, e que preencheram os seguintes critérios: (1) data de início do benefício entre 1o de janeiro de 2008 a 31 de dezembro de 2008 e (2) diagnósticos constantes da 10a revisão da Classificação Internacional de Doenças (CID10) compatíveis com doenças musculoesqueléticas na região cervical e/ou membros superiores, especificamente G56, G56.0, G56.1, G56.2, G56.3, G56.8, G56.9, M50, M50.0, M50.1, M50.2, M50.3, M50.8, M50.9, M53.1, M54.1, M54.2, M65, M65.2, M65.3, M65.4, M65.8, M65.9, M67, M67.8, M67.9, M70, M70.0, M70.8, M70.9, M75, M75.0, M75.1, M75.2, M75.3, M75.4, M75.5, M75,8, M75.9, M77, M77.0, M77.1, M79. Trabalhadores com história prévia de recebimento de benefício por doenças musculoesqueléticas na região cervical e/ou membros superiores relacionadas ao trabalho foram excluídos deste estudo.

Os dados provêm de três fontes. A primeira foi o Sistema Único de Benefícios (SUB), um sistema de registro de dados administrativos do Instituto Nacional do Seguro Social (INSS), no qual cada concessão de benefício é processada. Desses registros, foram utilizados dados sociodemográficos do segurado, o diagnóstico do agravo à saúde estabelecido pelo perito médico no primeiro exame médico-pericial para concessão do benefício, classificado por meio da CID-10, e a informação sobre existência de benefício anterior por doenças musculoesqueléticas na região cervical e/ou membros superiores relacionadas ao trabalho. A segunda foi o Cadastro Nacional de Informações Sociais (CNIS), uma base de dados nacional que contém informações cadastrais de trabalhadores empregados e contribuintes individuais, empregadores, vínculos empregatícios e remunerações, da qual se obtiveram 
informações sobre ocupação e ramo de atividade econômica. A terceira base nacional de dados foi a Relação Anual de Informações Sociais (RAIS) do Ministério do Trabalho e Emprego, que contém informações cadastrais de todos os trabalhadores empregados, de onde foram obtidos os denominadores por idade, sexo, renda e ramo de atividade econômica.

As seguintes variáveis foram analisadas: idade; sexo; situação empregatícia (empregado, desempregado); renda mensal paga pelo INSS, em salário mínimo (SM) (um SM = R\$415,00), utilizada como substituto da renda individual do segurado; ocupação e ramo de atividade econômica, empregando-se a Classificação Nacional de Atividades Econômicas (CNAE). Os pontos de corte adotados para categorização da idade e da renda corresponderam àqueles constantes nas tabulações já pré-definidas dessas variáveis na base de dados da RAIS.

Médias e/ou frequências das variáveis foram calculadas para caracterização dos casos. Foram estimadas a incidência cumulativa anual das doenças musculoesqueléticas na região cervical e/ ou membros superiores relacionadas ao trabalho e as razões de incidência cumulativa anual. Para o cálculo dos intervalos de $95 \%$ de confiança (IC95\%), foi empregado o método das séries de Taylor. Para a estimativa da incidência, utilizaram-se as informações do SUB para o numerador - número de segurados com doenças musculoesqueléticas na região cervical e/ou membros superiores relacionadas ao trabalho - e as informações da RAIS para o denominador - população empregada com carteira assinada. A base de dados do INSS e do CNIS foram fornecidas pela Auditoria Regional Salvador/INSS, e os dados da RAIS foram obtidos no sítio do Ministério do Trabalho e Emprego, após cadastramento específico. Os programas Epi Info versão 6.0 (Centers fosr Disease Control and Prevention, Atlanta, Estados Unidos) e Excel 2007 (Microsoft Corp., Estados Unidos) foram utilizados para a análise.

O projeto desta pesquisa foi aprovado pela Comissão de Ética em Pesquisa do Instituto de Saúde Coletiva da Universidade Federal da Bahia. O uso dos dados foi autorizado pela direção da Auditoria Regional Salvador/INSS.

\section{Resultados}

Em 2008, no Município de Salvador, o INSS concedeu 1.738 benefícios decorrentes das doenças musculoesqueléticas na região cervical e/ou membros superiores relacionadas ao trabalho, correspondendo a $32 \%$ de todos os benefícios ocupacionais, incluindo doenças e acidentes do trabalho. Esse total equivale a 1.692 trabalhadores, considerando que 46 destes receberam dois benefícios temporários no ano. Destes 1.692 trabalhadores, 972 foram considerados inelegíveis para o estudo, pois apresentavam histórico de recebimento de benefício em anos anteriores com diagnóstico compatível com doenças musculoesqueléticas na região cervical e/ou membros superiores relacionadas ao trabalho. O total de casos estudados, portanto, foi de 720 segurados.

Entre os casos, predominaram as mulheres $(66,9 \%)$ e os trabalhadores empregados $(93,5 \%)$. A idade média foi de 39 anos ( $D P=9,8)$. Os ramos de atividade econômica mais frequentes foram a indústria de transformação (17,2\%), o comércio (16,7\%) e as atividades administrativas/serviços complementares (15,7\%). A renda mensal média paga pelo INSS ao segurado foi de $\mathrm{R} \$ 912,55$ $(\mathrm{DP}=\mathrm{R} \$ 675,44)$. Receberam até dois SM 67\% dos segurados (Tabela 1).

Entre as ocupações, destacaram-se as funções bancárias $(7,5 \%)$, operador de telemarketing $(7,5 \%)$, operador de caixa $(6,7 \%)$, cozinheira/ auxiliar/ajudante de cozinha $(4,2 \%)$, auxiliar de serviços gerais (4\%) e auxiliar/técnico de enfermagem $(3,2 \%)$ (Tabela 2$)$.

Como diagnóstico principal, estabelecido pelo perito médico, predominaram as sinovites/tenossinovites (29\%), as lesões do ombro $(26,4 \%)$, as mononeuropatias de membros superiores $(25,8 \%)$ e as doenças da coluna cervical $(15,4 \%)$.

A incidência cumulativa anual das doenças musculoesqueléticas na região cervical e/ou membros superiores que geraram benefícios por incapacidade temporária relacionada ao trabalho foi de 14,6 casos por 10 mil trabalhadores. Entre as mulheres, foi três vezes maior do que entre os homens [risco relativo $(\mathrm{RR})=3,11$; IC95\%: 2,67-3,66]. Verificou-se aumento crescente da incidência a partir das faixas etárias mais jovens, culminando com a maior estimativa $(22,4 \times 10$ mil) entre trabalhadores com idade de cinquenta anos ou mais, quase quatro vezes maior do que a estimada para os mais jovens ( $R R=3,83$; IC95\%: 2,72-5,38). Esse padrão foi observado em ambos os sexos. Maior incidência cumulativa anual das doenças musculoesqueléticas na região cervical e/ou membros superiores (74,1 x $10 \mathrm{mil})$ foi verificada entre os segurados que receberam um $\mathrm{SM}$, o que correspondeu a mais de quatro vezes a incidência observada entre os que receberam cinco ou mais SM (RR = 4,37; IC95\%: 3,35-5,78). Por sua vez, entre os trabalhadores das faixas de renda 1,01-2,0 SM (RR = 0,66; IC95\%: 0,52-0,83) e 2,01-3,0 SM (RR =0,67; IC95\%: 0,50-0,92), as incidências cumulativas anuais foram menores que as do grupo que recebeu cinco ou mais SM. A análise por sexo e renda mostrou que, no 
Características sociodemográficas da população do estudo. Salvador, Bahia, Brasil, 2008 (N = 720).

\begin{tabular}{|c|c|c|}
\hline Variáveis & $\mathbf{n}$ & $\%$ \\
\hline \multicolumn{3}{|l|}{ Idade (anos) } \\
\hline $18-24$ & 46 & 6,4 \\
\hline $25-29$ & 98 & 13,6 \\
\hline $30-39$ & 237 & 32,9 \\
\hline $40-49$ & 221 & 30,7 \\
\hline $50+$ & 118 & 16,4 \\
\hline \multicolumn{3}{|l|}{ Sexo } \\
\hline Feminino & 482 & 66,9 \\
\hline Masculino & 238 & 33,1 \\
\hline \multicolumn{3}{|l|}{ Situação empregatícia } \\
\hline Empregado & 673 & 93,5 \\
\hline Desempregado & 47 & 6,5 \\
\hline \multicolumn{3}{|l|}{ Renda mensal paga pelo INSS (SM) } \\
\hline 1,00 & 152 & 21,1 \\
\hline $1,01-2,00$ & 331 & 46,0 \\
\hline $2,01-3,00$ & 76 & 10,6 \\
\hline $3,01-4,00$ & 39 & 5,4 \\
\hline $4,0,1-5,00$ & 36 & 5,0 \\
\hline $5,01+$ & 86 & 11,9 \\
\hline \multicolumn{3}{|l|}{ Ramo de atividade econômica } \\
\hline Indústrias de transformação & 124 & 17,2 \\
\hline Comércio & 120 & 16,7 \\
\hline Atividades administrativas e serviços complementares & 113 & 15,7 \\
\hline Atividades financeiras, de seguros e serviços relacionados & 77 & 10,7 \\
\hline Saúde humana e serviços sociais & 64 & 8,9 \\
\hline Construção & 38 & 5,3 \\
\hline Alojamento e alimentação & 37 & 5,1 \\
\hline Transporte, armazenagem e correios & 30 & 4,2 \\
\hline Outras atividades de serviços & 26 & 3,6 \\
\hline Educação & 23 & 3,2 \\
\hline Informação e comunicação & 18 & 2,5 \\
\hline Administração pública, defesa e seguridade social & 15 & 2,1 \\
\hline Água, esgoto, atividades de gestão de resíduos e descontaminação & 12 & 1,7 \\
\hline Atividades profissionais, científicas e técnicas & 12 & 1,7 \\
\hline Outras * & 11 & 1,5 \\
\hline
\end{tabular}

INSS: Instituto Nacional do Seguro Social; SM: salários mínimos.

* Indústrias extrativas, eletricidade e gás, artes, cultura, esporte e recreação, agricultura, pecuária, produção florestal, pesca e agricultura, atividades imobiliárias.

grupo de mulheres na faixa de renda de um salário mínimo, a incidência cumulativa anual foi de 123 casos por 10 mil, a de maior magnitude, bem superior às demais e mais de cinco vezes a incidência verificada entre o grupo que recebeu mais de cinco SM (RR = 5,10; IC95\%: 3,68-7,06) (Tabela 3).

Nos ramos de atividade econômica, as maiores incidências cumulativas anuais foram esti- madas entre os trabalhadores das "atividades financeiras e de seguros" (62,6 x 10 mil); em seguida estão as estimadas entre os da "indústria de transformação” (59,0 x 10 mil), valores correspondentes a mais de quatro vezes a incidência cumulativa anual da população total, respectivamente $\mathrm{RR}=4,28$ (IC95\%: 3,38-5,41) e RR = 4,03 (IC95\%: 3,34-4,88). O risco de os trabalhadores da agricultura, pecuária, produção florestal e pesca 
Ocupações da população do estudo. Salvador, Bahia, Brasil, 2008.

\begin{tabular}{|c|c|c|}
\hline Ocupação & n & $\%$ \\
\hline Gerente de banco/Caixa de banco/Técnico bancário/Escriturário & 54 & 7,5 \\
\hline Operador de telemarketing & 54 & 7,5 \\
\hline Operador de caixa (excluindo banco) & 48 & 6,7 \\
\hline Cozinheira/Auxiliar/Ajudante de cozinha & 30 & 4,2 \\
\hline Auxiliar de serviços gerais & 29 & 4,0 \\
\hline Auxiliar/Técnico de enfermagem & 23 & 3,2 \\
\hline Assistente/Auxiliar/Ajudante administrativo & 21 & 2,9 \\
\hline Balconista/Vendedor & 20 & 2,8 \\
\hline Costureira/Auxiliar de corte e costura & 19 & 2,6 \\
\hline Operador de produção/Auxiliar de produção & 16 & 2,2 \\
\hline Gari & 12 & 1,7 \\
\hline Pedreiro & 12 & 1,7 \\
\hline Motorista de ônibus & 11 & 1,5 \\
\hline Recepcionista & 8 & 1,1 \\
\hline Servente de obras & 8 & 1,1 \\
\hline Mecânico & 7 & 1,0 \\
\hline Professor & 6 & 0,8 \\
\hline Eletricista & 6 & 0,8 \\
\hline Camareira & 5 & 0,7 \\
\hline Carpinteiro & 5 & 0,7 \\
\hline Copeira & 5 & 0,7 \\
\hline Atendente & 5 & 0,7 \\
\hline Ajudante prático & 4 & 0,6 \\
\hline Faturista & 4 & 0,6 \\
\hline Pintor & 4 & 0,6 \\
\hline Secretária & 4 & 0,6 \\
\hline Alimentador de linha de produção & 3 & 0,4 \\
\hline Auxiliar de escritório & 3 & 0,4 \\
\hline Auxiliar de lavanderia & 3 & 0,4 \\
\hline Cobrador de ônibus & 3 & 0,4 \\
\hline Encanador & 3 & 0,4 \\
\hline Promotora de vendas & 3 & 0,4 \\
\hline Outras & 282 & 39,2 \\
\hline Total & 720 & 100,0 \\
\hline
\end{tabular}

terem benefício por incidência cumulativa anual das doenças musculoesqueléticas na região cervical e/ou membros superiores foi quase quatro vezes maior que o da população masculina total, todavia não foi estatisticamente significativo ( $R R=3,72$; IC95\%: 0,52-26,43), pois o número de trabalhadores nesse grupo foi de apenas um. "Atividades imobiliárias" (4,0 x 10 mil), "construção" (7,6 x 10 mil) e "transporte, armazenagem e correios" (7,8 x $10 \mathrm{mil})$ apresentaram as menores estimativas. Em todas as atividades econômicas, com trabalhadores de ambos os sexos incluídos, a incidência entre as mulheres sempre foi maior do que a verificada entre os homens. Para ambos os sexos, as maiores estimativas por ramo de atividade econômica foram similares às encontradas para a população em geral, exceto pela ordem, aparecendo a "indústria de transformação" em lugar das "atividades financeiras e de seguros” (Tabela 3).

O grupo de mulheres na faixa de renda de um SM apresenta a maior incidência cumulativa anual das doenças musculoesqueléticas na região cervical e/ou membros superiores: 123 x 10 mil. Constituiu-se de 130 seguradas (Tabela 3), entre as quais predominaram as seguintes 
Incidência cumulativa anual (ICA) * de doenças musculoesqueléticas na região cervical e/ou membros superiores relacionadas ao trabalho, conforme sexo, na população do estudo. Salvador, Bahia, Brasil, 2008 ( $N=720)$.

\begin{tabular}{|c|c|c|c|c|c|c|c|c|c|c|c|c|}
\hline \multirow[t]{2}{*}{ Variáveis } & \multicolumn{4}{|c|}{ Masculino } & \multicolumn{4}{|c|}{ Feminino } & \multicolumn{4}{|c|}{ Total } \\
\hline & $\mathrm{n}$ & ICA & RR & IC95\% & $\mathbf{n}$ & ICA & RR & IC95\% & n & ICA & RR & IC95\% \\
\hline Geral & 238 & 8,0 & 1,00 & - & 482 & 24,9 & 3,11 & $2,67-3,66$ & 720 & 14,6 & - & - \\
\hline \multicolumn{13}{|l|}{ Faixa etária (anos) } \\
\hline $18-24$ & 11 & 2,4 & 1,00 & - & 35 & 10,9 & 1,00 & - & 46 & 5,8 & 1,00 & - \\
\hline $25-29$ & 25 & 4,2 & 1,80 & $0,88-3,65$ & 73 & 17,1 & 1,58 & $1,05-2,36$ & 98 & 9,6 & 1,65 & $1,16-2,35$ \\
\hline $30-39$ & 69 & 7,3 & 3,10 & $1,64-5,85$ & 168 & 26,9 & 2,47 & $1,72-3,55$ & 237 & 15,1 & 2,59 & $1,89-3,55$ \\
\hline $40-49$ & 82 & 13,1 & 5,55 & $2,96-10,41$ & 139 & 35,8 & 3,29 & $2,27-4,76$ & 221 & 21,8 & 3,73 & $2,71-5,12$ \\
\hline $50+$ & 51 & 15,2 & 6,46 & $3,37-12,40$ & 67 & 38,6 & 3,54 & $2,36-5,33$ & 118 & 22,4 & 3,83 & $2,72-5,38$ \\
\hline \multicolumn{13}{|l|}{ Faixa de renda (SM) } \\
\hline 1,00 & 22 & 22,1 & 1,84 & $1,05-3,23$ & 130 & 123,2 & 5,10 & $3,68-7,06$ & 152 & 74,1 & 4,37 & $3,35-5,78$ \\
\hline $1,01-2,00$ & 108 & 6,1 & 0,51 & $0,35-0,74$ & 223 & 18,8 & 0,78 & $0,57-1,06$ & 331 & 11,1 & 0,66 & $0,52-0,83$ \\
\hline $2,01-3,00$ & 36 & 8,3 & 0,69 & $0,43-1,09$ & 40 & 17,4 & 0,72 & $0,48-1,09$ & 76 & 11,4 & 0,67 & $0,50-0,92$ \\
\hline $3,01-4,00$ & 24 & 11,4 & 0,89 & $0,53-1,49$ & 15 & 13,3 & 0,55 & $0,31-0,98$ & 39 & 12,1 & 0,71 & $0,49-1,04$ \\
\hline $4,01-5,00$ & 12 & 12,0 & 1,00 & $0,52-1,93$ & 24 & 37,2 & 1,54 & $0,95-2,50$ & 36 & 21,9 & 1,29 & $0,88-1,91$ \\
\hline $5,01+$ & 36 & 12,0 & 1,00 & - & 50 & 24,1 & 1,00 & - & 86 & 16,9 & 1,00 & - \\
\hline \multicolumn{13}{|l|}{$\begin{array}{l}\text { Ramo de atividade } \\
\text { econômica }\end{array}$} \\
\hline $\begin{array}{l}\text { Agricultura, pecuária, } \\
\text { produção florestal, } \\
\text { pesca }\end{array}$ & 1 & 29,7 & 3,72 & $0,52-26,43$ & - & - & - & - & 1 & 21,6 & 1,48 & $0,21-10,46$ \\
\hline Indústrias extrativas & 3 & 11,0 & 1,38 & $0,44-4,30$ & - & - & - & - & 3 & 8,6 & 0,59 & $0,19-1,84$ \\
\hline $\begin{array}{l}\text { Indústrias de } \\
\text { transformação }\end{array}$ & 58 & 42,5 & 5,33 & $4,00-7,10$ & 66 & 89,6 & 3,60 & $2,78-4,65$ & 124 & 59,0 & 4,03 & $3,34-4,88$ \\
\hline Eletricidade e gás & - & - & - & - & 3 & 52,3 & 2,10 & $0,68-6,52$ & 3 & 16,2 & 1,11 & $0,36-3,44$ \\
\hline $\begin{array}{l}\text { Água, esgoto, } \\
\text { atividades de gestão de } \\
\text { resíduos }\end{array}$ & 7 & 11,9 & 1,49 & $0,71-3,17$ & 5 & 37,1 & 1,49 & $0,62-3,59$ & 12 & 16,6 & 1,14 & $0,64-2,01$ \\
\hline Construção & 34 & 7,4 & 0,92 & $0,65-1,32$ & 4 & 10,8 & 0,44 & $0,17-1,18$ & 38 & 7,6 & 0,52 & $0,38-0,72$ \\
\hline Comércio & 27 & 4,0 & 0,51 & $0,34-0,75$ & 93 & 19,7 & 0,79 & $0,63-0,99$ & 120 & 10,5 & 0,72 & $0,59-0,87$ \\
\hline $\begin{array}{l}\text { Transporte, } \\
\text { armazenagem e correio }\end{array}$ & 23 & 7,0 & 0,87 & $0,57-1,34$ & 7 & 12,7 & 0,51 & $0,24-1,08$ & 30 & 7,8 & 0,53 & $0,37-0,77$ \\
\hline $\begin{array}{l}\text { Alojamento e } \\
\text { alimentação }\end{array}$ & 6 & 3,7 & 0,46 & $0,20-1,03$ & 31 & 21,9 & 0,88 & $0,61-1,26$ & 37 & 12,1 & 0,83 & $0,60-1,15$ \\
\hline $\begin{array}{l}\text { Informação e } \\
\text { comunicação }\end{array}$ & 9 & 13,2 & 1,66 & $0,85-3,22$ & 9 & 18,7 & 0,75 & $0,39-1,45$ & 18 & 15,5 & 1,06 & $0,66-1,69$ \\
\hline $\begin{array}{l}\text { Atividades financeiras e } \\
\text { de seguros }\end{array}$ & 23 & 40,2 & 5,04 & $3,29-7,73$ & 54 & 82,0 & 3,29 & $2,49-4,36$ & 77 & 62,6 & 4,28 & $3,38-5,41$ \\
\hline Atividades imobiliárias & - & - & - & - & 1 & 16,2 & 0,65 & $0,09-4,61$ & 1 & 4,0 & 0,28 & $0,04-1,96$ \\
\hline $\begin{array}{l}\text { Atividades profissionais, } \\
\text { científicas e técnicas }\end{array}$ & 5 & 5,9 & 0,74 & $0,30-1,78$ & 7 & 10,6 & 0,42 & $0,20-0,89$ & 12 & 7,9 & 0,54 & $0,31-0,96$ \\
\hline $\begin{array}{l}\text { Atividades } \\
\text { administrativas }\end{array}$ & 23 & 4,6 & 0,58 & $0,38-0,88$ & 90 & 31,2 & 1,25 & $1,00-1,57$ & 113 & 14,3 & 0,98 & $0,80-1,19$ \\
\hline $\begin{array}{l}\text { Administração pública, } \\
\text { defesa e seguridade }\end{array}$ & 2 & 4,4 & 0,56 & $0,14-2,24$ & 13 & 24,5 & 0,98 & $0,57-1,71$ & 15 & 15,3 & 1,05 & $0,63-1,74$ \\
\hline Educação & 4 & 3,6 & 0,45 & $0,17-1,21$ & 19 & 10,8 & 0,43 & $0,27-0,69$ & 23 & 8,0 & 0,55 & $0,36-0,83$ \\
\hline $\begin{array}{l}\text { Saúde humana e } \\
\text { serviços sociais }\end{array}$ & 6 & 4,8 & 0,60 & $0,27-1,34$ & 58 & 21,6 & 0,87 & $0,66-1,14$ & 64 & 16,2 & 1,11 & $0,86-1,43$ \\
\hline
\end{tabular}

(continua) 
Tabela 3 (continuação)

\begin{tabular}{|c|c|c|c|c|c|c|c|c|c|c|c|c|}
\hline \multirow[t]{2}{*}{ Variáveis } & \multicolumn{4}{|c|}{ Masculino } & \multicolumn{4}{|c|}{ Feminino } & \multicolumn{4}{|c|}{ Total } \\
\hline & $\mathbf{n}$ & ICA & RR & IC95\% & $\mathbf{n}$ & ICA & RR & IC95\% & $n$ & ICA & RR & IC95\% \\
\hline \multirow{2}{*}{\multicolumn{13}{|c|}{$\begin{array}{l}\text { Ramo de atividade } \\
\text { econômica }\end{array}$}} \\
\hline & & & & & & & & & & & & \\
\hline $\begin{array}{l}\text { Esportes, cultura e } \\
\text { recreação }\end{array}$ & 1 & 5,7 & 0,71 & $0,10-5,08$ & 2 & 17,4 & 0,70 & $0,17-2,80$ & 3 & 10,3 & 0,70 & $0,23-2,19$ \\
\hline $\begin{array}{l}\text { Outras atividades de } \\
\text { serviços }\end{array}$ & 6 & 6,8 & 0,85 & $0,38-1,91$ & 20 & 14,0 & 0,56 & $0,36-0,88$ & 26 & 11,2 & 0,77 & $0,52-1,14$ \\
\hline Todas & 238 & 8,0 & 1,00 & - & 482 & 24,9 & 1,00 & - & 720 & 14,6 & 1,00 & - \\
\hline
\end{tabular}

IC95\%: intervalo de 95\% de confiança; RR: risco relativo; SM: salários mínimos.

* Por 10 mil trabalhadores empregados com contrato de trabalho registrado em carteira.

ocupações: operadora de telemarketing (19\%), auxiliar de serviços gerais (16,2\%) e auxiliar de cozinha/cozinheira (12,3\%). Não foi possível estimar incidências cumulativas anuais especificas por grupos ocupacionais e por situação empregatícia em virtude da falta de denominadores desagregados.

\section{Discussão}

Neste estudo foi possível estimar medida de morbidade para as doenças musculoesqueléticas incapacitantes na região cervical e/ou membros superiores relacionadas ao trabalho, especificamente a incidência cumulativa anual de 15 casos por 10 mil trabalhadores integrantes do RGPS, com direito ao benefício acidentário no Município de Salvador, em 2008. Observou-se, também, que mulheres, os de menor renda, aqueles que trabalhavam no ramo de atividades financeiras e na indústria de transformação tinham maior risco de desenvolver essas enfermidades do que os seus referentes.

Além de a incidência cumulativa anual ser elevada, os benefícios por essas doenças representaram um montante de $32 \%$ de todos aqueles considerados como relacionados ao trabalho, o que demonstra a sua importância para a saúde pública. Não foram encontrados estudos nacionais que estimem incidência cumulativa anual para esse tipo de agravo em trabalhadores segurados. Algumas investigações foram realizadas com amostras de populações empregadas em empresas, apresentando estimativas de prevalência de todos os casos, não considerando a incapacidade. A incidência cumulativa anual estimada no presente estudo foi quase cinco vezes maior do que a calculada com registros de doença do trabalho em empregados do setor privado nos Estados Unidos, de 3,2 por 10 mil trabalha- dores para doenças incapacitantes causadas por esforço repetitivo, em 2008 9. Ressalte-se, entretanto, que os critérios de classificação das doenças musculoesqueléticas na região cervical e/ou membros superiores podem ser distintos, além de os casos registrados nos Estados Unidos incluírem afastamentos do trabalho a partir de um dia, enquanto o presente estudo se limitou a trabalhadores com 15 ou mais dias de afastamento. $\mathrm{O}$ alto risco para esses agravos incapacitantes, conforme mostrado neste estudo, pode ser atribuído a formas de organização dos processos de trabalho, caracterizadas pela intensificação das atividades, com consequente exigência de uso excessivo e repetitivo do sistema osteomuscular; some-se a isso a alta demanda psicossocial no trabalho, como tem sido extensivamente referido por vários autores 6,7,10. Vale destacar, ainda, que, em 2007, o INSS, com base em evidências de sub-registro de agravos, promoveu mudança na sistemática do estabelecimento do nexo entre o agravo e o trabalho, aperfeiçoando o registro de doenças relacionadas ao trabalho no Brasil.

Essa mudança compreendeu especificamente três aspectos: a não obrigatoriedade de o trabalhador portar a Comunicação do Acidente de Trabalho no momento do exame médico pericial, a automação de listas das doenças relacionadas ao trabalho no Sistema Informatizado de Perícias Médicas e a ampliação das possibilidades de nexo com o advento do Nexo Técnico Epidemiológico Previdenciário, resultado de um estudo epidemiológico realizado pela Previdência Social que identificou associações de agravos geradores de benefícios previdenciários com ramos de atividades econômicas. Isso acarretou acréscimo significativo no número desses agravos no país, a exemplo das doenças musculoesqueléticas, cujo registro aumentou $517 \%$ no período referente aos 11 meses seguintes à implantação dessa mudança, em comparação com os 11 meses ante- 
riores 11. Esse crescimento sugere a ocorrência de uma expressiva subnotificação de doenças do trabalho no país previamente às modificações no estabelecimento do nexo.

Outros estudos sobre doenças musculoesqueléticas na região cervical e/ou membros superiores relacionadas ao trabalho apresentaram resultados não comparáveis aos desta investigação, pois abordaram populações ocupacionais específicas ou população trabalhadora total, incluindo autônomos e funcionários públicos; além disso, consideraram todos os casos, independentemente da gravidade, e se basearam em dados autorreferidos. Na Inglaterra, por exemplo, inquérito sobre doenças musculoesqueléticas na região cervical e/ou membros superiores relacionadas ao trabalho, incapacitantes ou não, relatadas pela própria população, mostrou incidência de 28 casos por 10 mil trabalhadores 12 , estimativa superior às encontradas para Salvador e Estados Unidos.

A maior incidência de doenças musculoesqueléticas na região cervical e/ou membros superiores entre mulheres, conforme verificado neste estudo, é corroborada por diversas investigações e revisões de literatura sobre prevalência e incidência desse agravo 13,14,15,16,17,18,19,20. São diversas as explicações para esse achado. Alguns autores o atribuem à divisão sexual do trabalho, com predominância das mulheres em atividades sedentárias, repetitivas, rotineiras, além da sobrecarga do trabalho doméstico 17 . Outras explicações referem-se à maior vulnerabilidade feminina, causada por diferenças hormonais 21 e por locais e instrumentos de trabalho inapropriados para mulheres, uma vez que estes são projetados para homens, desconsiderando as diferenças antropométricas entre os sexos 22. Punnett \& Hebert 23, citados por Treaster \& Burr 18, assinalam que a diferença de morbidade por gênero poderia se constituir meramente em um viés de informação, com mulheres apresentando maior probabilidade de relatar mais sintomas e de buscar cuidados médicos do que os homens. Esta última hipótese foi questionada com base em uma revisão de literatura que mostrou evidências da existência de uma real diferença entre os gêneros no tocante ao risco de doenças musculoesqueléticas na região cervical e/ou membros superiores. Segundo o estudo, tal diferença não pode ser atribuída exclusivamente ao viés de informação ou a fatores relacionados ao trabalho, mas, sim, a uma combinação de diferenças biológicas, culturais e psicossociais entre homens e mulheres, que podem ser acentuadas por fatores de trabalho físicos e psicossociais 18 .

Maior morbidade musculoesquelética entre os trabalhadores mais velhos evidenciada neste estudo tem sido verificada também em diversas investigações 14,24,25. Esse efeito da idade sobre a morbidade estaria relacionado a mudanças biológicas decorrentes do processo do envelhecimento, a exemplo de alterações degenerativas dos discos intervertebrais, tendões, ligamentos, entre outras. Ademais, deve ser considerado o maior número de anos de exposição a demandas físicas e psicossociais do trabalho, o que pode estar associado ao aumento do risco para esses agravos 14,24 .

O presente estudo não demonstrou gradiente de renda para a ocorrência de doenças musculoesqueléticas na região cervical e/ou membros superiores relacionadas ao trabalho. Todavia, em ambos os sexos, foi verificada maior incidência entre os segurados que receberam um SM, quando comparados com os de outros grupos; chamou atenção, ainda, nesta faixa salarial, a incidência de 123 casos por 10 mil mulheres, que se destacou, sobremaneira, das demais. A ausência de gradiente de renda sugere que essa morbidade no estrato de renda mais baixo entre as mulheres esteja relacionada à pobreza ou a ambientes e condições de trabalho extremamente precários, e não à desigualdade socioeconômica relativa 26. Segundo Kaplan 27, a não linearidade da associação entre posição socioeconômica e um determinado evento transfere o foco do gradiente para onde se concentra o volume do excesso de risco, que é, no presente estudo, o grupo de mulheres de renda muito baixa, com predomínio para as ocupações de operadora de telemarketing, auxiliar de serviços gerais e auxiliar de cozinha/cozinheira. Para assegurar o emprego, esse grupo mais vulnerável de trabalhadoras deve estar se submetendo a condições de trabalho bastante precárias, com demandas físicas muito adversas e baixo controle sobre o trabalho. Ressalte-se que são necessários estudos específicos para esclarecimento da incidência mais baixa verificada entre o grupo de renda também baixa (1,01-2,00 $\mathrm{SM})$, em relação aos grupos com renda acima de quatro SM.

A desigualdade socioeconômica na morbidade vem sendo evidenciada para uma série de problemas de saúde, inclusive as doenças musculoesqueléticas, sejam as lombalgias, sejam as dores na região cervical e/ ou membros superiores 26,28. Distribuição diferencial das condições de trabalho entre grupos sociais distintos poderia explicar as diferenças socioeconômicas na incidência das doenças musculoesqueléticas 26,28,29. Um estudo realizado com trabalhadores da cidade de Helsinque, na Finlândia, encontrou gradiente de classe ocupacional para doenças musculoesqueléticas, explicado por demandas físicas no trabalho em ambos os sexos, cuja ocorrência foi 
maior entre as mulheres do que entre os homens, sugerindo maior vulnerabilidade relacionada a gênero ${ }^{30}$. Lidar com demandas psicossociais do trabalho, especificamente controle - possibilidade de tomar decisões - sobre o trabalho, ser criativo e usar e desenvolver novas habilidades podem estar implicadas na associação entre posição socioeconômica e saúde, sejam como mediadoras, sejam como modificadoras do efeito daquela associação 31 .

As maiores incidências de doenças musculoesqueléticas na região cervical e/ou membros superiores foram encontradas nos ramos de atividade econômica "finanças" e "indústria da transformação". Surpreendentemente, "construção civil" e "transportes, armazenagem e correios" mostraram as menores estimativas, considerando que nesses setores estão presentes fatores de risco para doenças musculoesqueléticas na região cervical e/ou membros superiores. Em relação a esse último achado, vale notar que outros fatores sociais têm um papel importante no registro dos agravos relacionados ao trabalho, além das condições deste, como sindicalização, tamanho das empresas 32 . Alta rotatividade e informalidade dos contratos de trabalho, condições habituais na construção civil, podem estar relacionadas com a baixa ocorrência de casos registrados nesse ramo de atividade econômica 33 .

Estudos em outros países também têm estimado incidências e/ou prevalências elevadas de doenças musculoesqueléticas na região cervical e/ou membros superiores relacionadas ao trabalho na indústria de transformação. Entretanto, diferentemente do observado no presente estudo, as atividades financeiras não se encontravam entre os ramos de atividades com as maiores estimativas 12,13,32,34. Fatores relacionados à organização e gestão do trabalho podem explicar essa diferença e precisam ser focalizados em estudos futuros.

Dificuldade de acesso dos trabalhadores do ramo de atividade "agricultura, pecuária, produção florestal, pesca” aos benefícios previdenciários e informalidade dos contratos de trabalho podem explicar o número insignificante de acometidos pelo agravo mostrado neste estudo, uma vez que essas atividades podem abranger diversas situações de risco para doenças musculoesqueléticas na região cervical e/ou membros superiores.

Os resultados encontrados devem ser analisados considerando-se as limitações da base de dados, já que, neste estudo, utilizaram-se dados administrativos do sistema de informação da Previdência Social e do Ministério do Trabalho e Emprego, coletados para outros objetivos. Outro limite foram os denominadores, os quais corresponderam à população empregada com contrato de trabalho registrado em carteira, que trabalhava em Salvador, enquanto os numeradores corresponderam à população empregada residente naquele município. Isso pode ter levado a distorções nas estimativas de incidência cumulativa anual, para as quais não foi possível determinar a direção. Dados censitários mais apropriados para os denominadores, referentes à população empregada residente em Salvador e sua distribuição por sexo, idade, renda e ramo de atividade econômica, estavam disponíveis apenas para o ano 2000.

Este estudo contribui com informação original sobre a incidência cumulativa anual das doenças musculoesqueléticas incapacitantes na região cervical e/ou membros superiores, que representa a magnitude do problema na população de trabalhadores integrantes do RGPS coberta pelo Seguro Acidente do Trabalho, e mostra a relevância desse problema de saúde pública. A investigação identificou, também, um grupo muito vulnerável para a ocorrência desses agravos - o das mulheres de baixa renda. Isso sugere desigualdade econômica e de gênero na ocorrência dessas enfermidades, indicando a necessidade de priorizar não só ações de prevenção nos locais de trabalho, com foco na ergonomia e organização do trabalho, como também o diagnóstico precoce, tratamento e reabilitação profissional. Medidas não foram ajustadas por covariáveis para ressaltar os dados brutos. Os achados indicam a necessidade da realização de novos estudos sobre gênero, desigualdades sociais e doenças musculoesqueléticas na região cervical e/ou membros superiores para esclarecimento das diferenças encontradas. 


\section{Resumo}

Estimou-se a incidência cumulativa anual (ICA) das doenças musculoesqueléticas incapacitantes que acometem a região cervical elou membros superiores (DMEMS) relacionadas ao trabalho, entre trabalhadores do Regime Geral da Previdência Social (RGPS) de Salvador, Bahia, Brasil. Trabalhadores que receberam benefícios por incapacidade temporária por DMEMS relacionadas ao trabalho foram considerados casos, em 2008. Os dados provêm dos sistemas administrativos do Instituto Nacional do Seguro Social (INSS) e do Ministério do Trabalho e Emprego (MTE). A ICA foi de 15 por dez mil trabalhadores. Mulheres, os de menor renda e aqueles que trabalhavam no ramo de atividades financeiras e indústria de transformação tinham maior ICA-DMEMS do que os seus referentes. Mulheres com o menor rendimento (um salário mínimo: $R \$$ 415,00) tiveram a maior ICA-DMEMS, de 123 casos por dez mil. Isso sugere desigualdade na ocorrência dessas enfermidades, indicando a necessidade de priorizar não só ações de prevenção, com foco na ergonomia e organização do trabalho, como também o diagnóstico precoce, tratamento e reabilitação profissional.

Transtornos Traumáticos Cumulativos; Benefícios do Seguro; Saúde do Trabalhador; Incidência

\section{Referências}

1. Leigh JP, Robbins JA. Occupational disease and worker's compensation: coverage, costs, and consequences. Milbank Q 2004; 82:689-721.

2. Kraut A. Estimates of the extent of morbidity and mortality due to occupational diseases in Canada. Am J Ind Med 1994; 25:267-78.

3. Buckle PW, Devereux JJ. The nature of work-related neck and upper limb musculoskeletal disorders. Appl Ergon 2002; 33:207-17.

4. Souza NSS, Santana VS, Albuquerque-Oliveira PR, Barbosa-Branco A. Doenças do trabalho e benefícios previdenciários relacionados à saúde, Bahia, 2000. Rev Saúde Pública 2008; 42:630-8.

\section{Colaboradores}

N. S. S. Souza concebeu o projeto, analisou e interpretou os dados; redigiu o manuscrito e aprovou a versão final. V. S. Santana contribuiu na interpretação dos dados; revisou o manuscrito e aprovou a versão final.

\section{Agradecimentos}

À Auditoria Regional em Salvador, Bahia, do Instituto Nacional do Seguro Social, pela cessão dos dados utilizados neste estudo. Ao Conselho Nacional de Desenvolvimento Científico e Tecnológico (CNPq), pela bolsa de produtividade em pesquisa (processo $n^{\circ} .522621 / 96-1$ ) concedida à V. S. Santana.
5. National Research Council/Institute of Medicine. Musculoskeletal disorders and the workplace: low back and upper extremities. Washington DC: National Academy Press; 2001.

6. Sato L. LER: objeto e pretexto para a construção do campo trabalho e saúde. Cad Saúde Pública 2001; 17:147-52.

7. Wünsch Filho V. Perfil epidemiológico dos trabalhadores. Rev Bras Med Trab 2004; 2:103-17.

8. Cheadle A, Franklin G, Wolfhagen C, Savarino J, Liu PY, Salley C, et al. Factors influencing the duration of work-related disability: a population-based study of Washington State workers' compensation. Am J Public Health 1994; 84:190-6. 
9. Bureau of Labor Statistics. Nonfatal occupational injuries and illness requiring days away from work. Washington DC: United States Department of Labor; 2008 .

10. Fernandes RCP, Assunção AA, Carvalho FM. Mudanças nas formas de produção na indústria e a saúde dos trabalhadores. Ciênc Saúde Coletiva 2010; 15 Suppl 1:1563-74.

11. Ministério da Previdência Social. Cultura de prevenção. http://www.ciss.org.mx/assembly/pdf/ pt/2008/remigio_todeschini_pt.pdf (acessado em 14/Jun/2010).

12. Health and Safety Executive. Self-reported workrelated illness and workplace injuries in 2008/09: results from the Labour Force Survey. http://www. hse.gov.uk/statistics/ifs/ifs0809.pdf (acessado em 09/Jun/2010).

13. Gun TR. The incidence and distribution of RSI in South Australia 1980-81 to 1986-87. Med J Aust 1990; 153:376-80.

14. Zwart BCH, Broersen JPJ, Frings-Dresen MHW, van Dijk FJH. Musculoskeletal complaints in the Netherlands in relation to age, gender and physically demanding work. Int Arch Occup Environ Health 1997; 70:352-60.

15. Brage S, Nygard JF, Tellnes G. The gender gap in musculoskeletal-related long term sickness absence in Norway. Scand J Soc Med 1998; 26:34-43.

16. Zwart BCH, Frings-Dresen MHW, Kilbom A. Gender differences in upper extremity musculoskeletal complaints in the working population. Int Arch Occup Environ Health 2001; 74:21-30.

17. Strazdins L, Bammer G. Women, work and musculoskeletal health. Soc Sci Med 2004; 58:997-1005.

18. Treaster DE, Burr D. Gender differences in prevalence of upper extremity musculoskeletal disorders. Ergonomics 2004; 47:495-526.

19. Huisstede BMA, Bierma-Zeinstra SMA, Koes BW, Verhaar JAN. Incidence and prevalence of upperextremity musculoskeletal disorders. A systematic appraisal of the literature. BMC Musculoskelet Disord 2006; 7:7.

20. Fernandes RCP, Assunção AA, Silvany Neto AM, Carvalho FM. Musculoskeletal disorders among workers in plastic manufacturing plants. Rev Bras Epidemiol 2010; 13:11-20

21. Chiang HC, Ko YC, Chen SS, Yu HS, Wu TN, Chang PY. Prevalence of shoulder and upper-limb disorders among workers in the fish-processing industry. Scand J Work Environ Health 1993; 19:126-31.

22. Karlqvist LK, Bernmark E, Ekenvall L, Hagberg M, Isaksson A, Rosto $\mathrm{T}$. Computer mouse position as a determinant of posture, muscular load and perceived exertion. Scand J Work Environ Health 1998; 24:62-73.
23. Punnett L, Hebert R. Work-related musculoskeletal disorders: Is there a gender differential, and if so, what does it mean? In: Goldman MB, Hatch MC, editors. Women and health. San Diego: Academic Press; 2000. p. 474-92.

24. Cassou B, Derriennic F, Monfort C, Norton J, Touranchet A. Chronic neck and shoulder pain, age, and working conditions: longitudinal results from a large random sample in France. Occup Environ Med 2002; 59:537-44.

25. Broersen JP, de Zwart BC, van Dijk FJ, Meijman TF, van Veldhoven M. Health complaints and working conditions experienced in relation to work and age. Occup Environ Med 1996; 53:51-7.

26. Landsbergis PA. Assessing the contribution of working conditions to socioeconomic disparities in health: a commentary. Am J Ind Med 2010; 53:95-103.

27. Kaplan GA. Health inequalities and the welfare state: perspectives from social epidemiology. Nor Epidemiol 2007; 17:9-20.

28. Punnett L. Socioeconomic differences in severe back morbidity. Occup Environ Med 2006; 63: 369-70.

29. Schrijvers CTM, van de Mheen HD, Stronks K, Mackenbach JP. Socioeconomic inequalities in health in the working population: the contribution of working conditions. Int J Epidemiol 1998; 27:1011-8.

30. Aittomaki A, Lahelma E, Rahkonen O, Leino-Arjas P, Martikainen P. The contribution of musculoskeletal disorders and physical workload to socioeconomic inequalities in health. Eur J Public Health 2006; 17:145-50.

31. Siegrist J, Marmot M. Health inequalities and the psychosocial environment - two scientific challenges. Soc Sci Med 2004; 58:1463-73.

32. Morse T, Dillon C, Kenta-Bibi E, Weber J, Diva U, Warren N, et al. Trends in work-related musculoskeletal disorder reports by year, type, and industrial sector: a capture-recapture analysis. Am J Ind Med $2005 ; 48: 40-9$

33. Santana VS, Oliveira RP. Saúde e trabalho na construção civil em uma área urbana do Brasil. Cad Saúde Pública 2004; 20:797-811.

34. Cherry NM, Meyer JD, Chen Y, Holt DL, McDonald JC. The reported incidence of work-related musculoskeletal disease in the UK: MOSS 1977-2000. Occup Med 2001; 51:450-45.

Recebido em 15/Mai/2011

Versão final reapresentada em 14/Ago/2011 Aprovado em 22/Ago/2011 